\title{
In Vitro Solubility and Release Profile Correlation with pKa Value of Efavirenz Polymorphs
}

Yoga Windhu Wardhana ${ }^{1 *}$, Eli Nur Aisyah ${ }^{1}$, Iyan Sopyan ${ }^{1,2}$, and Taofik Rusdiana ${ }^{1}$

${ }^{1}$ Department of Pharmaceutics and Pharmaceuticals Technology, Faculty of Pharmacy, Universitas Padjadjaran (UNPAD), Indonesia.

${ }^{2}$ Study Center of Drug Discovery and Drug Development, Faculty of Pharmacy, Universitas Padjadjaran (UNPAD), Indonesia.

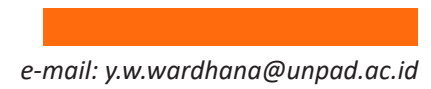

\section{ABSTRACT}

Efavirenz (EFV) was approved by the United States Food and Drug Administration in 1998 with no polymorphic forms, but further research defined 23 different forms, including amorphous and solvated forms. This study aims to determine the ability of dissolved EFV polymorphs in in vitro media kinetic release models of pKa values. The polymorph types were obtained through various organic solvents such as acetonitrile, n-hexane, and methanol, i.e., form I, II, and III. The characteristics were distinguished by polarisation microscopy, differential scanning calorimetry (DSC), Fourier transform infrared (FTIR), and Raman spectroscopy. The solubility and dissolution of each polymorph were examined by adding $0.25 \%$ sodium lauryl sulphate (SLS) to the comparative dissolution media (water, $\mathrm{HCl}$ at $\mathrm{pH} 1.2$, phosphate buffer at $\mathrm{pH}$ 4.6 and 6.8). The different microscopic shapes provided a unique fingerprint in the FTIR and the Raman spectra. The thermal behaviour examination provided a DSC thermogram with a specific melting point for each polymorph. The results of the solubility and dissolution tests reported that the highest peak was reached by form II, followed by forms III and I. These followed the pKa values of each polymorph, namely 10.12, 10.63, and 10.37 for form I, II, and III, respectively. The dissolution profile shows that $\mathrm{pH}$ conditions affect the release kinetics of form I compared to the metastable forms. The kinetic model of form I is pH-dependent; the acidic medium provided a slower release rate. Unlike the metastable forms, drug loading remained constant but still followed Higuchi's kinetic release model, even in acidic medium.

KEYWORDS: Polymorphism, efavirenz, pKa, solubility, dissolution kinetics, dissolution

\section{INTRODUCTION}

$\mathrm{n}$ pharmaceutical development, the solubility and permeability of active drug compounds are significant concerns. In recent times, many active drugs on the market have been difficult to dissolve, so solubility needs to be increased to achieve therapeutic purposes. Improvements in drug solubility occur directly using different formulations and various technological applications such as comminution, complexation, or micellization, regardless of enhancing the intrinsic properties of the active pharmaceutical ingredient (API). One of these properties is the presence of polymorphisms, i.e., when differences in the solid form of the same drug structure can yield different properties, including dissolution in water (1).

In In this study, the exhibited polymorphic compound was efavirenz (EFV), with the chemical name (S)-6-chloro4-(cyclopropylethynyl)-1,4-dihydro-4-(trifluoromethyl)-
2(H)-3,1-benzoxazine-2-one. Initially, EFV was approved in 1998 by the United States Food and Drug Administration (US FDA) with no polymorphic forms, but further research has discovered 23 different forms, including amorphous and solvated forms (2-16). Generally, the most stable form is preferred in the solid dosage form, but its limited solubility poses a challenge (17).

Improvements in the solubility of EFV have been reported in some studies through the preparation of co-crystals, the addition of superdisintegrant excipients, surfactants or cosolvency, amorphization, and the application of some technologies such as nanoemulsions, nanosuspensions, nanoparticles, and complex inclusion (10, 18-31). Some solid dispersion techniques are also used, including comminution to reduce particle size (22, 32-38). Apart from these methods, the use of other metastable forms that are theoretically more soluble is not well known. Some metastable polymorphic forms of EFV have been

* Corresponding author. 
investigated as an alternative $(2,7,10,13,19)$. Based on previous studies, we obtained metastable forms with better water solubility, namely forms II and III. However, the solubility of these forms in the gastrointestinal segment has not been reported yet (16). These metastable forms are easily changed by grinding and heat $(39,40)$. However, there is a lack of information regarding the in vitro solubility and the pKa range of selected polymorphs. Therefore, this study was conducted to complement the absence of pKa (acid dissociation constant) information on the corresponding polymorphs.

\section{MATERIALS AND METHODS}

\section{Materials}

Pharmaceutical grade EFV (batch no. EZ1670711, Hetero Labs. Ltd., India) was purchased from PT Kimia Farma Tbk, Indonesia. Analytical grade solvents for recrystallisation, such as acetonitrile, n-hexane, and methanol (Merck, USA), were used in this work. All solvents used were of analytical reagent grade without further purification. For solubility, dissolution, and pKa determinations, the materials used were $\mathrm{HCl}, \mathrm{NaCl}, \mathrm{KCl} \mathrm{NaOH}, \mathrm{Na}_{2} \mathrm{HPO}_{4}$, $\mathrm{NaH}_{2} \mathrm{PO}_{4}, \mathrm{KH}_{2} \mathrm{PO}_{4}$, sodium lauryl sulphate (SLS), potassium hydrogen phthalate (KHP), and boric acid $\left(\mathrm{H}_{3} \mathrm{BO}_{3}\right)$. All reagents used were of analytical grade from J.T. Baker Chemicals. All reagents and buffers were prepared with water distillation (aquadest) and were $\mathrm{CO}_{2}$-free.

\section{Preparation of EFV Polymorphs (Form I, II, and III)}

The solid-state forms were made by the recrystallisation of crude EFV in analytical grade organic solvents. Acetonitrile, $\mathrm{n}$-hexane, and methanol and were named form I, II, and III, respectively.

\section{Characterisation of Polymorphs}

The resulting polymorphic forms were observed using polarizing light microscopy (PLM). The morphology of polymorphs was observed using an Olympus BX53 model ULH100-3 microscope (400 $\mathrm{x}$ ). The sample was placed on a microscope slide and covered with a coverslip.

\section{Differential Scanning Calorimetry (DSC)}

Thermal behavior of the polymorphs was assessed using a Netzsch DSC 214 Polyma and an aluminium crucible. About 1-3 mg of the sample was measured under a dynamic nitrogen atmosphere and a heating rate of 10 ${ }^{\circ} \mathrm{C} / \mathrm{min}$ in the range of $30-250{ }^{\circ} \mathrm{C}$. Before usage, the DSC device was calibrated with indium as a standard reference.

\section{Fourier Transform Infrared (FTIR) Spectroscopy}

The specific fingerprints of the solid-state sample were monitored on a multi-scope spectrophotometer (IR Prestige-21, Shimadzu, Japan) by sealing the sample between two $\mathrm{KBr}$ plates using a hydraulic press at $200 \mathrm{~kg} /$ $\mathrm{cm}^{2}$ for $15 \mathrm{~s}$ to form a disc. The spectrum for each sample was analyzed in the spectral region of $500-2500 \mathrm{~cm}^{-1}$ with a resolution of $4 \mathrm{~cm}^{-1}$.

\section{Raman Spectroscopy}

Raman spectra of each polymorph was recorded using a Bruker-Senterra Micro-Raman spectrophotometer with a diode laser system $(785 \mathrm{~nm}, 100 \mathrm{~mW})$ as the excitation source for spectrum recording at room temperature in the spectral region of $500-2500 \mathrm{~cm}^{-1}$.

\section{Prediction of pKa Values}

Prediction of pKa values of all polymorphs was performed by spectrophotometric measurement in buffers with a $\mathrm{pH}$ range of 1.2-9. Preparation of buffers at $\mathrm{pH}$ between 1.24 was conducted using $\mathrm{HCl}, \mathrm{NaCl}$, and $\mathrm{KHP}$ with different compositions. At pH 5, KHP and $\mathrm{NaOH}$ were used, and at $\mathrm{pH} 6$ and 7, $\mathrm{KH}_{2} \mathrm{PO}_{4}$ and $\mathrm{NaOH}$ were used. Meanwhile, at $\mathrm{pH} 8$ and 9, $\mathrm{H}_{3} \mathrm{BO}_{3}, \mathrm{KCl}$, and $\mathrm{NaOH}$ were used following the Indonesian Pharmacopeia (41). Samples (10 mg) were dissolved in a methanol and buffer solution with a ratio of 4:6 up to $100 \mathrm{~mL}$, and the $\mathrm{pH}$ result was checked using a Mettler Toledo S20 pH meter. The sample solution was filtered through Millipore $0.45-\mu \mathrm{m}$ filter paper and suitably diluted before measurement by UV spectroscopy at $248 \mathrm{~nm}$.

\section{Calibration Curve Drug Content in Simulated Gastrointestinal Medium}

Standard solutions of EFV were made by dissolving 10 $\mathrm{mg}$ of untreated EFV in methanol and $0.25 \% \mathrm{w} / \mathrm{v}$ SLS solution $(1: 9 \mathrm{v} / \mathrm{v})$, then slowly adding it to simulated

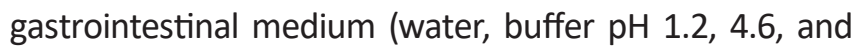
6.8) up to $100 \mathrm{~mL}$. Then, the standard solution was dilute to various concentrations, i.e., 5, 7, 9, 11, and $13 \mathrm{ppm}$. Those standard solutions were measured by double beam UV-vis spectrophotometry (SPECORD 200, Analytic Jena) at $248 \mathrm{~nm}$. The absorbance of each standard solution was recorded and plotted as a calibration curve to determine the linear regression equation for the standard calculation.

\section{Saturation In Vitro Solubility Studies}

Approximately $10 \mathrm{mg}$ of each sample was dissolved in $100 \mathrm{~mL}$ of each simulated gastrointestinal medium. The media were prepared at the $\mathrm{pH}$ of the gastrointestinal tract, i.e., $\mathrm{pH} 1.2,4.6$, and 6.8. The samples were agitated in the solutions using a mechanical agitator at $120 \mathrm{rpm}$ for 24 hours at room temperature. Before measurement, the sample solution was filtered through $0.45-\mu \mathrm{m}$ filter paper and suitably diluted. The sample solution was measured by UV spectroscopy at $248 \mathrm{~nm}$.

\section{Comparative In Vitro Dissolution Studies}

The four dissolution media employed were water, 
$0.1 \mathrm{~N} \mathrm{HCl}$, and phosphate buffer $\mathrm{pH} 4.5$ and 6.8. The dissolution of each polymorph was performed according to USP 36-NF 31, based on the USP monograph for EFV using 1-2\% w/v SLS (42). However, based on biorelevant considerations, $0.25 \% \mathrm{w} / \mathrm{v}$ SLS was also used $(1,17)$. The dissolution assessment was performed $50 \mathrm{rpm}$ and at a temperature of $37 \pm 0.5{ }^{\circ} \mathrm{C}$ in a Sotax AG CH-4008 BASEL type AT-6 apparatus (USP apparatus 4). Sample solutions were withdrawn at specific intervals up to the 60 -min point, then filtered through $0.45-\mu \mathrm{m}$ filter paper. Collected samples were suitably diluted with dissolution medium and analyzed at $248 \mathrm{~nm}$ using double beam UVVis spectrophotometry.

\section{Assessment of In Vitro Comparative Dissolution Kinetics}

Drug release data were fitted to the correlation coefficient $\left(R^{2}\right)$ with the best-fit kinetic model to determine the dissolution behavior as follows. The kinetic models used to describe the behavior were zero-order, first-order, and Higuchi, which represent drug release controlled by the Fickian diffusion process. The mathematic representation of these kinetic release models is:

- Zero-order: $C_{t}=C_{0}-k t$

- First-order: $\operatorname{Ln} C_{t}=\operatorname{Ln} C_{0}-k t$

- Higuchi: $Q=A \sqrt{D\left(2 C_{0}-C_{t}\right) C_{t} t} \rightarrow Q=k H \sqrt{t}$.

In these equations, $C_{\mathrm{t}}$ is the amount of drug dissolved at time $t$; $\mathrm{CO}$ is the initial amount of drug in the solution (usually $t=0$ ); $Q$ is the amount of drug released over time $t$ per unit area $A ; D$ is the diffusivity of the drug molecules (diffusion coefficient) in the matrix substance; $k$ is the release order rate constant; and $k H$ is the Higuchi dissolution rate constant (43).

\section{RESULTS AND DISCUSSION}

Pharmaceutical scientists have already discussed polymorphisms in APl; this was reported in 2000 (1). Polymorphisms can affect the final quality of pharmaceutical products, and choosing the correct API at an early point in development is essential. To achieve solidstate differentiation for production of polymorphs, several methods are used, including controlling crystallisation conditions (dissolution, temperature, seeding, stirring) or uncontrollable formation resulting from improper handling in the production process (44-48). In this study, recrystallisation was used for polymorph production, which involves dissolving the API in different solvents. The resulting polymorphs need to be appropriately evaluated due to their different physical structures. In this study, PLM, DSC, and FTIR and Raman spectroscopy were used Dissolution to evaluate three EFV polymorphs.

\section{Characterisation of Polymorphs}

Physical variation of EFV polymorphs was first observed visually in a Petri dish and confirmed by PLM $(400 \mathrm{x})$, as shown in Figure 1. The results show that form I was smoother than the other polymorphs and has a powderlike form. In plain view, form II was granule-shaped, and form III looked like needles. By PLM, form I was birefringent crystalline, form II resembled a stack of boards, and form III looked like a haystack or needles. These results confirm that polymorphs can be obtained using organic solvents of different polarity, as previously reported (16).
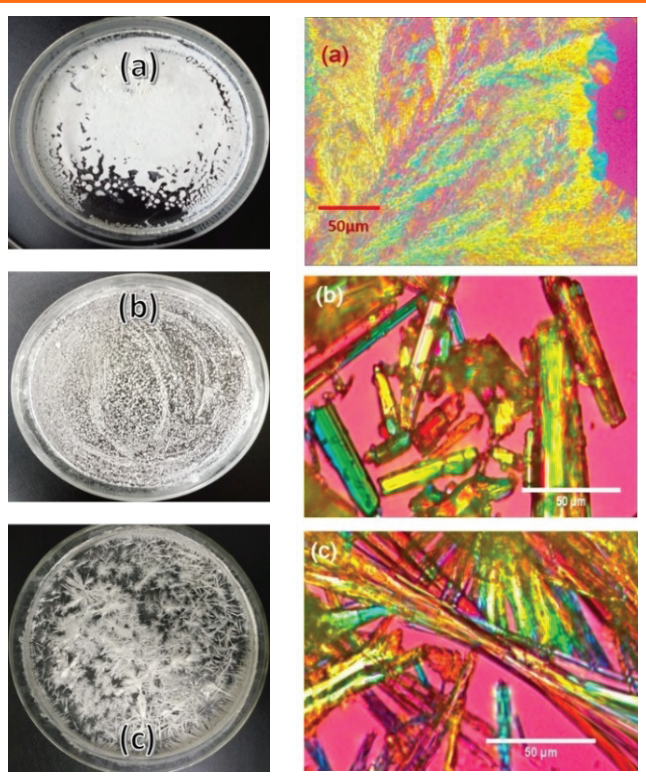

Figure 1. The difference in morphological polymorphs was seen visually and microscopically through polarizing light microscopy (400 x) from each efavirenz polymorph: (a) form I, (b) form II, and (c) form III.

Furthermore, the DSC method was adopted, and the vibration of the EFV molecular groups was also assessed. As shown in Figure 2, the stable polymorph was form I, and the others (form II and III) had an exothermic peak obtained at different temperatures, which indicates conversion to a stable form. Those polymorphs were found at different temperatures, i.e., forms I, II, and $\mathrm{III}$, appeared at $139.5,120$, and $108.4{ }^{\circ} \mathrm{C}$, respectively. The thermograms show that the polymorphs were successfully created, as previously published (16). However, this needed further confirmation regarding the functional groups of the different structures. This functional group shifting was detected via the IR spectra. Shifts in the vibration of functional groups in the IR spectra were recorded using FTIR and Raman spectroscopy, and these spectrographs complemented each other; FTIR spectroscopy shows the movement of polar functional groups, while Raman spectra show the 
shifts in semipolar to non-polar functional groups. Figure 3 shows similarities in the spectral patterns; Raman spectra had more shifting peaks than FTIR, which means that the polarizability has changed in these polymorphs. Furthermore, these changes affect other properties such as solubility. The wavenumber region from 500-2500 $\mathrm{cm}^{-1}$ was enough to represent the shifting of functional groups from $\mathrm{CF}_{3}$, benzoxazine, and cyclopropyl in the EFV molecule (49). The deformation of trifluoromethyl groups showed symmetric and antisymmetric stretches around $660-800 \mathrm{~cm}^{-1}$ and $1100-1200 \mathrm{~cm}^{-1}$, respectively. For benzoxazine, there were two different modes of polarity, while aromatic rings are easily obtained in the Raman spectrum around 1390-1500 $\mathrm{cm}^{-1}$. On the contrary, the oxazine ring is more visible in the IR spectrum between the range of $1745-1840 \mathrm{~cm}^{-1}$. Cyclopropyl ring groups can be identified in IR and Raman spectrum bands at 1430 $\mathrm{cm}^{-1}$ for ${ }_{\delta}\left(\mathrm{CH}_{2}\right)$ deformation, $1330-1370 \mathrm{~cm}^{-1}$ for planar (CH) bonds, $1040-1075 \mathrm{~cm}-1$ for ${ }_{\omega}\left(\mathrm{CH}_{2}\right)$ wagging modes, and around $800-840 \mathrm{~cm}^{-1}$ for ${ }_{\rho}\left(\mathrm{CH}_{2}\right)$ rocking bonds (49). The representatives of these functional group shifts are clearly shown in the Raman spectra in Figure 3 , at around $1700 \mathrm{~cm}^{-1}$ for the benzoxazine ring, $1300 \mathrm{~cm}^{-1}$ for the cyclopropyl ring, and $600-800 \mathrm{~cm}^{-1}$ for trifluoromethyl $\left(\mathrm{CF}_{3}\right)$ groups.

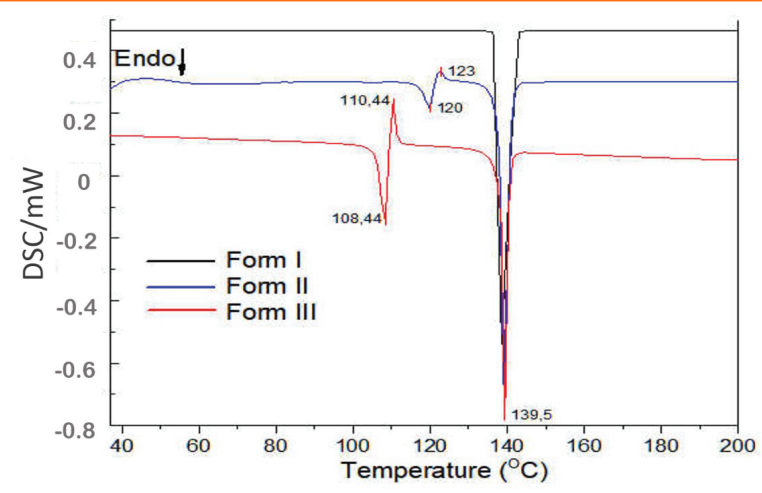

Figure 2. Thermal behavior of each efavirenz polymorph (form I, II, and III). Endo: endoterm.

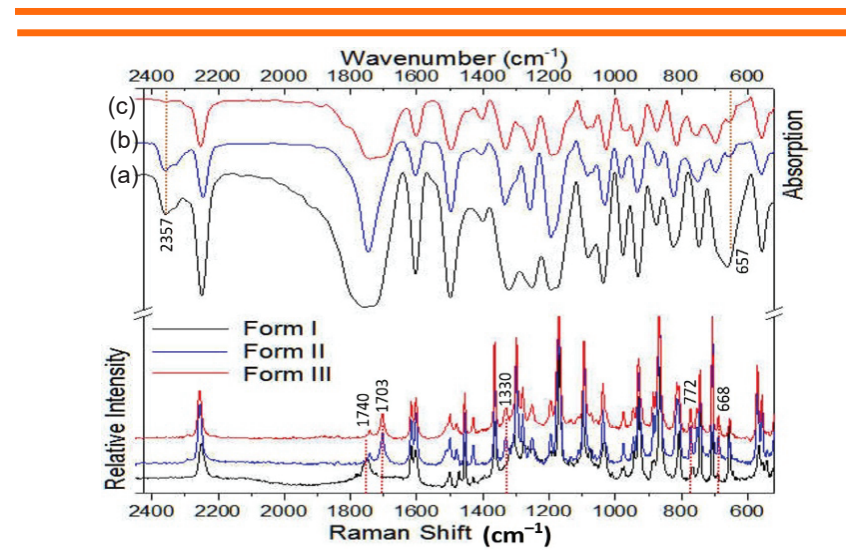

Figure 3. Differences spectrum of fourier transform infrared (FTIR) and Raman spectroscopy from each efavirenz polymorph: (a) form I, (b) form II, and (c) form III.

\section{Prediction of pKa Values}

Polarizability changes due to different orientation of functional groups may alter the polymorph's ionic strength, because most drug molecules are ionisable. The ionisation state plays an essential role in the bioavailability rate-limiting step, and at a given $\mathrm{pH}$, it indicates the $\mathrm{pKa}$ (50). The pKa value of different polymorphic forms is rarely investigated, even though it immensely affects the absorption ability of drugs in different compartments of the digestive tract with different $\mathrm{pH}$ values (51).

There are methods to predict the pKa value. In this study, UV-Vis spectrophotometry was used for practical considerations $(50,52)$. The principle of pKa value prediction follows the Henderson-Hasselbalch equation (52).

Using spectroscopy methods, the pKa value is determined by plotting absorbance logarithmically as a function of $\mathrm{pH}$; this results in a sigmoid curve, where the inflection point corresponds to the pKa. From Figure 4 and Table 1, it was found that the pKa values of polymorph forms I, II, and III were 10.116, 10.628, and 10.372 , respectively. From the previous reference, using spectrophotometric and $\mathrm{pH}$ solubility studies, it was found that the pKa value was $10.1 \pm 0.1$ (53). These experimental results indicate that the calculation is consistent with the reference, considering that only form I is widely used. Based on this result, polarizability changes among polymorphs can alter the ionic strength and affect the drug's intrinsic solubility.

Table 1. Linearity Equation for Efavirenz pKa Calculations

\begin{tabular}{|c|c|c|c|}
\hline $\begin{array}{c}\text { EFV } \\
\text { Polymorph }\end{array}$ & Linearity Equation & $\begin{array}{c}\text { Coefficient } \\
\text { Correlation } \\
\left(\boldsymbol{R}^{2}\right)\end{array}$ & pKa value \pm SD \\
\hline Form I & $y=0.094 x-0.9509$ & 0.8630 & $10.1159 \pm 0.0084$ \\
\hline Form II & $y=0.0833 x-0.8853$ & 0.8054 & $10.6278 \pm 0.0108$ \\
\hline Form III & $y=0.0897 x-0.9304$ & 0.8186 & $10.3723 \pm 0.0249$ \\
\hline
\end{tabular}

\section{Calibration curve of the drug content in simulated gastrointestinal medium}

Before the solubility of a drug is defined, a calibration curve should be determined based on the differences in solubility at each $\mathrm{pH}$ of simulated gastrointestinal solution. The slope of the calibration curve for each measurement was almost the same. Therefore, the linear equation of the calibration curve can be used as a reference standard to calculate the solubility assays in vitro. Based on the calculation results, the linear equations, with EFV content in ppm as $x$ and absorbance of spectroscopy as $y$, for each in vitro medium are: 


\section{Determination of pKa from selected EFV polymorphs}

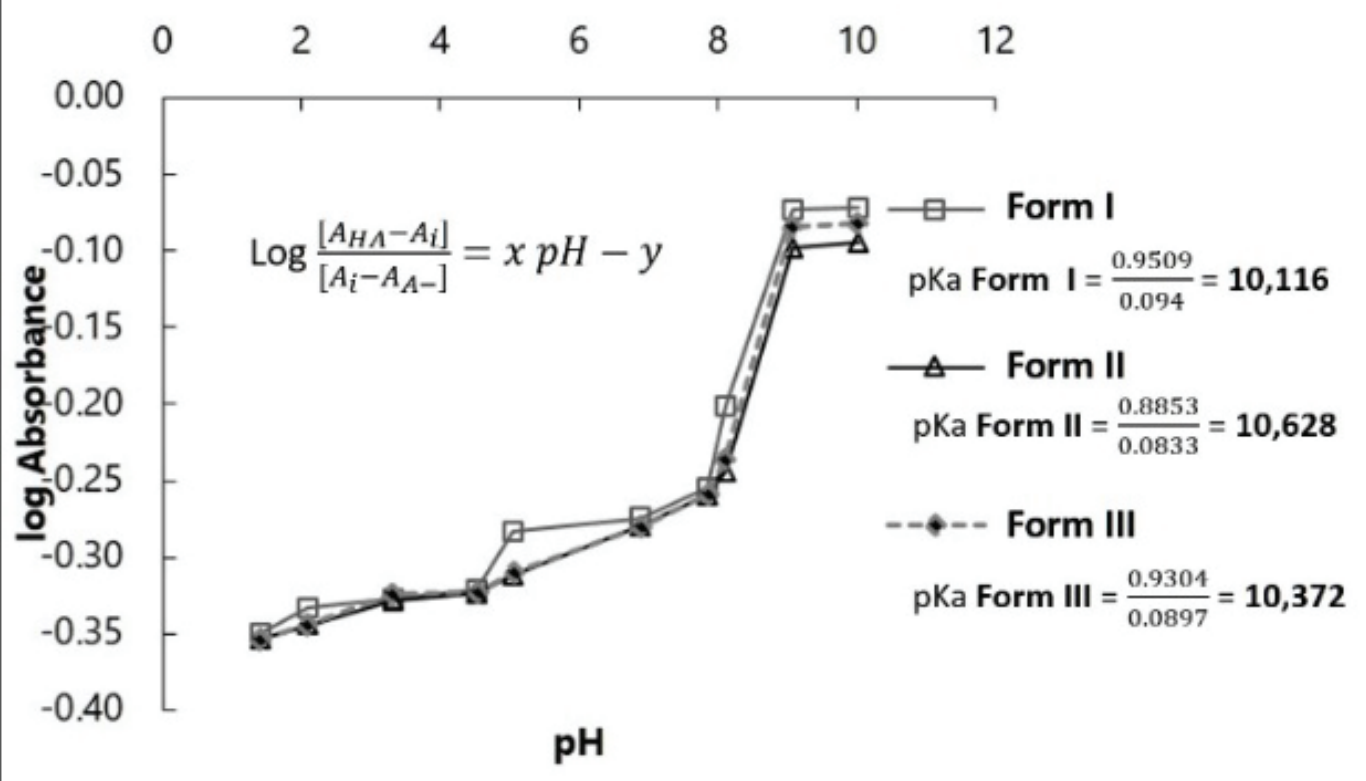

Figure 4. Spectrophotometric method for prediction of pKa with plots of Log Abs. vs pH for each EFV polymorph (form I, II, and III) at room temperature. EFV: efavirenz; Abs: absorbance; $A_{H A}$ : concentration of non-dissociated acid; $A_{i}: p K a ; A_{A}$ : concentration of dissociated acid.

- $y=0.0436 x+0.0449\left(R^{2}=0.9997\right)$ for water;

- $y=0.0467 x+0.0109\left(R^{2}=0.9995\right)$ for buffer $\mathrm{pH} 6.8$;

- $y=0.0444 x+0.0086\left(R^{2}=0.9994\right)$ for buffer $\mathrm{pH} 4.6$;

- $y=0.0446 x+0.0130\left(R^{2}=0.9998\right)$ for buffer $\mathrm{pH} 1.2$.

\section{Saturation In Vitro Solubility Studies}

Solubility studies of EFV have been well-established in regular dissolution media (USP requirement monograph), and several discriminative dissolution methods have been developed $(37,54,55)$. However, solubility studies of different polymorphic forms of EFV in a comparative in vitro medium have not been reported.

Solubility results for each EFV polymorph in simulated gastrointestinal medium showed agreement with the predicted pKa values (Fig. 5). Form II had the greatest solubility in each medium, followed by forms III and I. The highest overall solubility level was in the buffer medium at $\mathrm{pH} 1.2$ (simulated gastric fluid), as EFV is a weak base that is quickly absorbed in the stomach.

\section{Comparative In Vitro Dissolution Studies}

As shown in Figure 6, form II was always higher in the overall $\mathrm{pH}$ conditions of the simulated gastrointestinal tract fluids. This result confirms that form II, with the best pKa value, has the highest solubility level compared to the others. This improved solubility, and dissolution of forms II and III show that both are metastable forms, even though form I is stable. According to the DSC thermogram, the thermodynamic relationship of polymorphic transition between polymorphs is monotropically related. Therefore, the metastable form will dissolve first in water as it melts faster than the stable form at a given room pressure. The thermogram results are consistent with the van't Hoff equation, where enthalpy of the crystal lattice of the metastable state is less than that of the stable state (53). This enthalpy also causes form II to dissolve faster than III, which has shorter endothermic peaks than form III with a larger endothermic peak.

\section{Assessment of In Vitro Comparative Dissolution Kinetics}

The dissolution data were then plotted into the selected kinetic model equation, i.e., zero-order, first-order, and the Higuchi model. The models were chosen to represent the immediate and extended release of common drugs (39). Table 2 shows that the polymorphs had $\mathrm{pH}$ dependent dissolution behavior, especially for form I, which tended to slow down in increasingly acidic media, even though the highest solubility was found for acidic $\mathrm{pH}$. Meanwhile, for the metastable forms, the rate of release was unaffected by changes in $\mathrm{pH}$.

\section{CONCLUSION}

In this study, the systematic relationship between changes 
\% Netral 폴 $\mathrm{pH} 6.8 \quad \mathrm{pH} 4.6 \quad$ IIII $\mathrm{pH} 1.2$

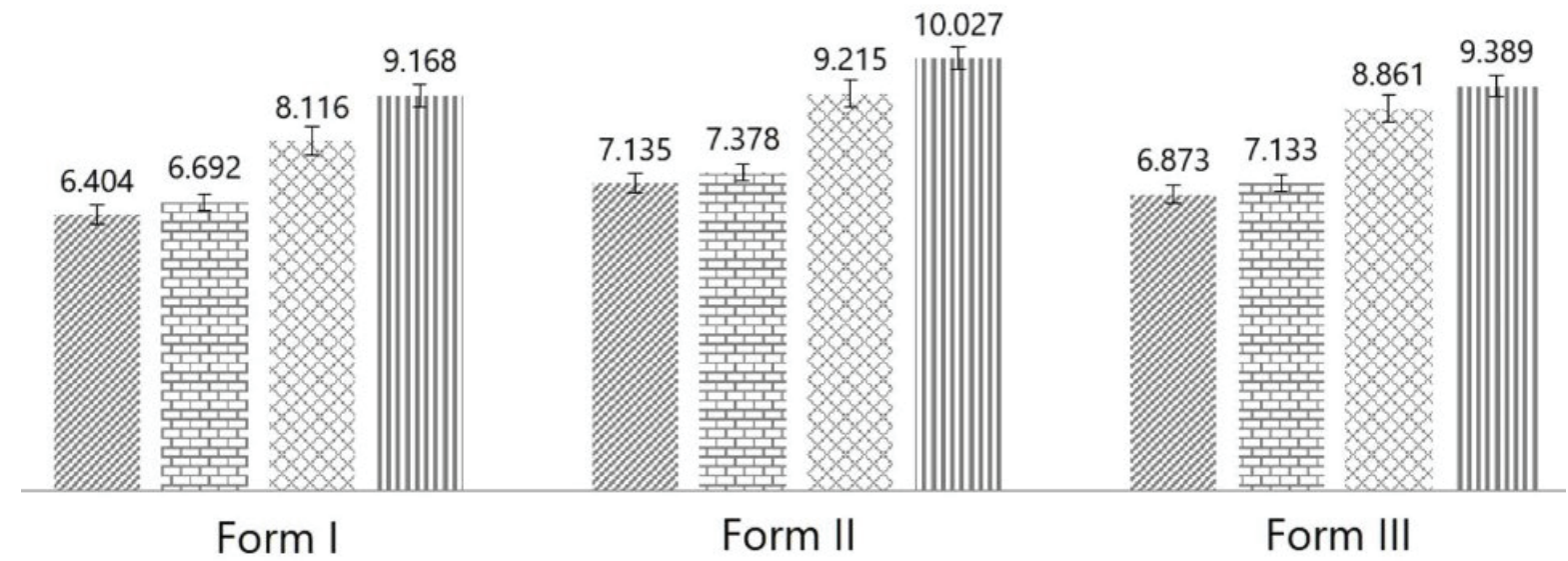

Figure 5. Solubility (mean ppm $\pm S D$ ) of each efavirenz polymorph (form I, II, and III) in various in vitro dissolution media.
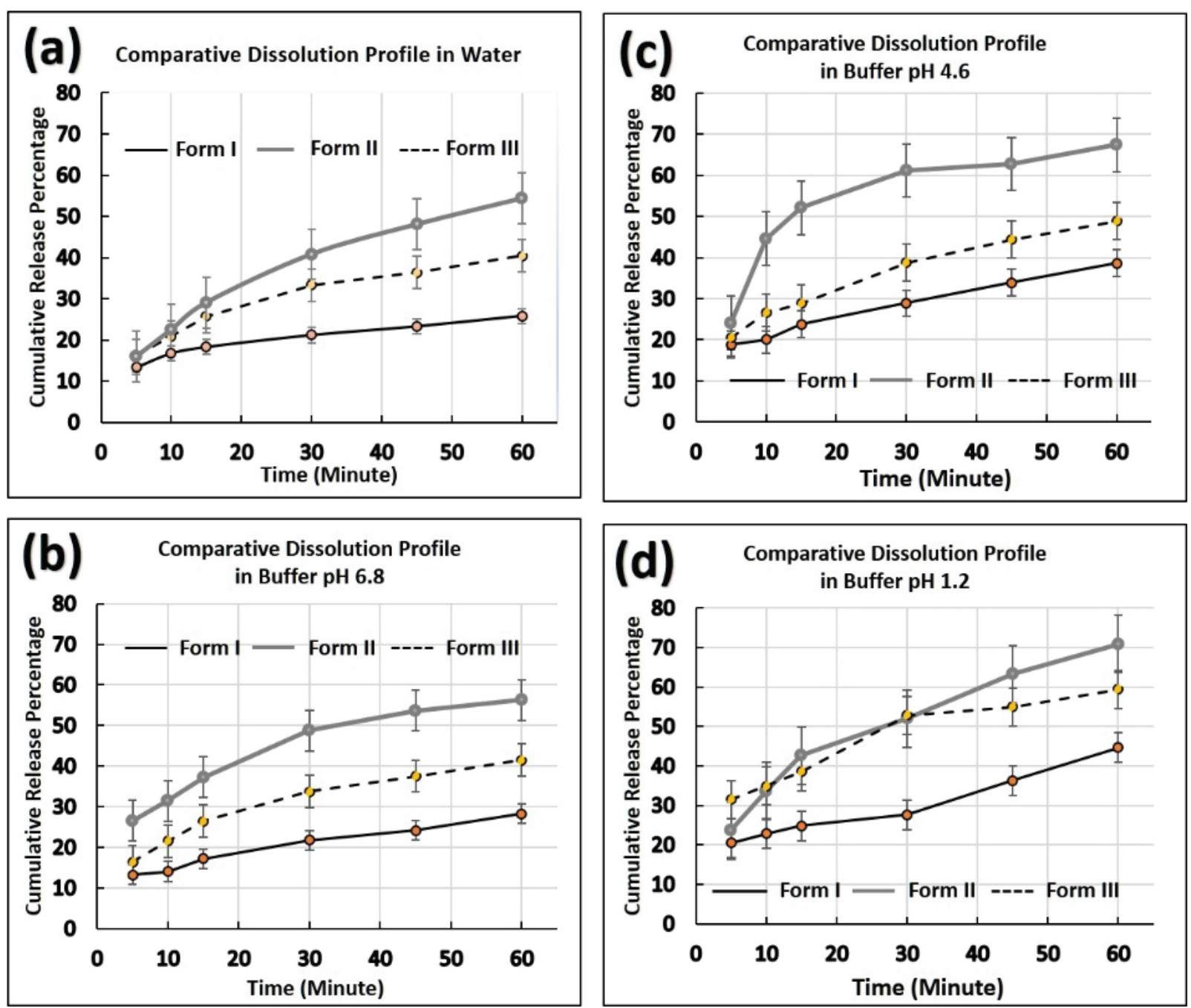

Figure 6. Comparative in vitro dissolution profile of efavirenz polymorphs (form I, II, and III) in (a) water and (b) pH 6.8, (c) pH 4.6, and (d) pH 1.2 buffer solutions. 


\begin{tabular}{|c|c|c|c|}
\hline EFV Polymorph & Zero Order Model & First Order Model & Higuchi Model \\
\hline \multicolumn{4}{|l|}{ Water } \\
\hline Form I & 0.9420 & 0.8872 & 0.9840 \\
\hline Form II & 0.9524 & 0.8764 & 0.9959 \\
\hline Form III & 0.9316 & 0.8647 & 0.9838 \\
\hline \multicolumn{4}{|l|}{ Phosphate Buffer, pH 6.8} \\
\hline Form I & 0.9793 & 0.9483 & 0.9863 \\
\hline Form II & 0.9213 & 0.8767 & 0.9771 \\
\hline Form III & 0.9331 & 0.8616 & 0.9331 \\
\hline \multicolumn{4}{|l|}{ Phosphate Buffer, pH 4.6} \\
\hline Form I & 0.9914 & 0.9682 & 0.9887 \\
\hline Form II & 0.7265 & 0.6064 & 0.8351 \\
\hline Form III & 0.9639 & 0.9122 & 0.9957 \\
\hline \multicolumn{4}{|l|}{ Hydrochloric Acid, pH 1.2} \\
\hline Form I & 0.9722 & 0.9865 & 0.9200 \\
\hline Form II & 0.9524 & 0.8655 & 0.9900 \\
\hline Form III & 0.9239 & 0.8983 & 0.9664 \\
\hline
\end{tabular}

in the structure of a drug substance into polymorphs, ionic strength, and solubility are clearly explained, with EFV as an example. It was found that the rank of solubility and dissolution rate were form II $>\mathrm{III}>$ and I, respectively. The predicted pKa of each polymorph was 10.116, 10.628, and 10.372 for form I, II, III, respectively. Based on the representations of kinetic release models, it was found that form I has a $\mathrm{pH}$-dependent dissolution behavior that tends to slow down in acidic medium.

\section{ACKNOWLEDGEMENTS}

The authors acknowledge PT Kimia Farma Tbk, Indonesia for supplying the pure efavirenz, PT LMS for supportive assistance, and the School of Pharmacy-ITB and Faculty of Pharmacy-UNPAD for providing laboratory facilities.

\section{FUNDING}

This work was supported by a Fundamental Research Grant from the Ministry of Research and Technology and National Research and Innovation Agency (KEMENRISTEK) BRIN) of the Republic of Indonesia (Contract No. 1827/ UN6.3.1/LT/2020), which was provided by the Directorate of Research, Community Service, and Innovation (DRPMI) - UNPAD.

\section{CONFLICTS OF INTEREST}

The authors disclosed no conflicts of interest related to this article.

\section{REFERENCES}

1. Higashi, K.; Ueda, K.; Moribe, K. Recent progress of structural study of polymorphic pharmaceutical drugs. Adv. Drug Deliv. Rev. 2017, 117, 71-85. DOI: 10.1016/j.addr.2016.12.001.

2. Chadha, R.; Saini, A.; Arora, P.; Jain, D.V.S. An insight into thermodynamic relationship between polymorphic forms of efavirenz. J Pharm. Pharm. Sci. 2012, 15, 234-251. DOI: 10.18433/J3J30Z.

3. Clarke, W.; Crocker, L. S.; Kukura J. L. Process for the crystallization of reverse transcriptase inhibitor using an anti-solvent, US Patent WO 1998/033782, June 8, 1998.

4. Cuffini, S.; Howie, R. A.; Tiekink, E. R. T.; Wardell, J. L.; Wardell, S. M. S. V. (S)-6-Chloro-4-cyclo-propylethynyl-4-trifluoromethyl1H-3,1-benzoxazin-2(4H)-one. Acta Crystallogr. 2009, E6, 31703171.

5. Doney, J. A. Amorphous efavirenz and the production thereof. US Patent 2007/0026073 A1, February 1, 2007.

6. Dova, E. Polymorphic forms of efavirenz. Patent WO 2008/108630, December 9, 2008.

7. Fandaruff, C.; Rauber, G. S.; Araya-Sibaja, A. M.; Pereira, R. N.; de Campos, C. E. M.; Rocha, H. V. A.; Monti, G. A.; Malaspina, T.; Silva, M. A. S.; Cuffini, S. L. Polymorphism of anti-HIV drug afavirenz: investigation on thermodynamic and dissolution properties. Cryst. Growth Des. 2014, 14, 4968-4975. DOI: 10.1021/cg500509c.

8. Khanduri, H.C.; Panda, A.K.; Kumar, Y. Processes for the preparation of polymorphs of efavirenz, Patent WO 2006/030299 A1, March 23, 2006. 
9. Mahapatra, S.; Thakur, T. S.; Joseph, S.; Varughese, S.; Desiraju, G. R. Solid state forms of the anti-HIV drug efavirenz. Conformational flexibility and high Z issues. Cryst. Growth Des. 2010, 10, 3191-3202. DOI: 10.1021/cg100342k.

10. Perold, Z.; Swanepoel, E.; Brits, M. Anomalous dissolution behaviour of a novel amorphous form of efavirenz. Am. J. Pharm Tech Res. 2012, 2, 272-292.

11. Radesca, L.; Maurin, M.; Rabel, S.; Moore, J. Crystalline efavirenz, International Patent WO 99/64405, December 16, 1999.

12. Radesca, L.; Maurin, M.; Rabel, S.; Moore, J. Crystalline efavirenz, US Patent 6,673,372 B1, January 1, 2004.

13. Ravikumar, K.; Sridhar, B. Molecular and crystal structure of efavirenz, a potent and specific inhibitor of HIV-1 reverse transcriptase, and its monohydrate. Mol. Cryst. Liq. Cryst. (Phila. Pa.) 2009, 515, 190-198. DOI: 10.1080/15421400903291434.

14. Reddy, B.P.; Rathnakar, K.; Reddy, R.R.; Reddy, D.M.; Reddy, K.S.C. Novel polymorphs of efavirenz. US Patent 2006/0235008 A1, October 19, 2006.

15. Sharma, R.; Bhushan, H.K.; Aryan, R.C.; Singh, N.; Pandya, B.; Kumar, Y. Polymorphic forms of efavirenz and processes for their preparation. WO 2006/040643 A2, April 20, 2006.

16. Wardhana, Y. W.; Soewandhi, S. N.; Wikarsa, S.; Suendo, V. Polymorphic properties and dissolution profile of efavirenz due to solvents recrystallization. Pak. J. Pharm. Sci. 2019, 32, 981986.

17. Raza. K.; Kumar, P.; Ratan, S.; Malik, R.; Arora, S. Polymorphism: the phenomenon affecting the performance of drugs. SOJ Pharm. Pharm. Sci. 2014, 1, 1-10. DOI: 10.15226/23746866/1/1/00111.

18. Chadha, R.; Saini, A.; Arora, P.; Chanda, S.; Jain, D. V. S. Cocrystals of efavirenz with selected coformers: preparation and characterization. Int. J. Pharm. Pharm. Sci. 2012, 4, 244-250.

19. de Melo, A. C. C.; de Amorim, I. F.; Cirqueira, M.; Martins, F. T. dL.; Martins, F.T. Toward novel solid state forms of the anti-HIV drug efavirenz: from low screening success to cocrystals engineering strategies and discovery of a new polymorph. Cryst. Growth Des. 2013, 13, 1558-1569. DOI: 10.1021/cg3018002.

20. Chowdary, K. P. R.; Naresh, A. Formulation development of efavirenz tablets employing $\beta$ cyclodextrin-PVP K30-SLS: a factorial study. J. Appl. Pharm. Sci. 2011, 1, 130-134.

21. da Costa, M. A.; Lione, V. O. F.; Rodrigues, C. R.; Cabral, L. M.; Rocha, H. V. A. Efavirenz dissolution enhancement II: aqueous co-spray-drying. Int. J. Pharm. Sci. Res. 2015, 6, 3807-3820.

22. da Costa, M. A.; Seiceira, R. C.; Rodrigues, C. R.; Hoffmeister, C. R. D.; Cabral, L. M.; Rocha, H. V. A. Efavirenz dissolution enhancement I: co-micronization. Pharmaceutics 2012, 5, 1-22.

23. Chika, M.; Edwin, O.; Gerald, U. Study on the influence of cosolvent and surfactant on solubilization of efavirenz. Eur. J. Pharm. Med. Res. 2016, 3, 522-526.

24. Sathigari, S. K.; Radhakrishnan, V. K.; Davis, V. A.; Parsons, D. L.; Babu, R. J. Amorphous-state characterization of efavirenz--polymer hot-melt extrusion systems for dissolution enhancement. J. Pharm. Sci. 2012, 101, 3456-3464. DOI: 10.1002/jps.23125.

25. Kumar, V. K.; Devi, M. A.; Bhikshapathi, D. V. R. N. Development of solid self-emulsifying drug delivery systems containing efavirenz: in vitro and in vivo evaluation. Int. J. Pharm. Bio. Sci. 2013, 4, 869-882.

26. Kommavarapu, P.; Maruthapillai, A.; Palanisamy, K. Preparation and characterization of efavirenz nanosuspension with the application of enhanced solubility and dissolution rate. HIV AIDS Rev. 2016, 15, 170-176. DOI: 10.1016/j.hivar.2016.11.007.

27. Dharshini, K. P.; Devi, D. R.; Hari, B. N. V. Effect of nanotechnology approaches on anti-retroviral molecule: efavirenz. Curr. Org. Chem. 2018, 22, 2634-2643. DOI: 10.2174/138527282266618 1116122616.

28. Gaur, P. K.; Mishra, S.; Bajpai, M.; Mishra, A. Enhanced oral bioavailability of efavirenz by solid lipid nanoparticles: in vitro drug release and pharmacokinetics studies. BioMed Res. Int. 2014, 2014, 363404. DOI: 10.1155/2014/363404.

29. Varshosaz, J.; Taymouri, S.; Jahanian-Najafabadi, A.; Alizadeh, A. Efavirenz oral delivery via lipid nanocapsules: formulation, optimisation, and ex-vivo gut permeation study. IET Nanobiotechnol. 2018, 12, 795-806. DOI: 10.1049/ietnbt.2018.0006.

30. Chowdary, K. P. R.; Ravikumar, M.; Madhuri, Ch. P. S. R. Enhancement of solubility of efavirenz employing $\beta-C d$ and SLS: optimization by 22 factorial design. World J. Pharm. Res. 2015, 4, 1004-1009.

31. Vyas, M.; Jain, H.; Sharma, R.; Dharwekar, G. N. Solubility enhancement of efavirenz (BCS Class II Drug) by cyclodextrin inclusion complex technique. J. Drug Deliv. Ther. 2017, 7, 41-43.

32. Fitriani, L.; Haqi, A.; Zaini, E. Preparation and characterization of solid dispersion freeze-dried efavirenz - polyvinylpyrrolidone K-30. J. Adv. Pharm. Technol. Res. 2016, 7, 105-109. DOI: 10.4103/2231-4040.184592.

33. Lavra, Z. M. M.; Pereira de Santana, D.; Ré, M. I. Solubility and dissolution performances of spray-dried solid dispersion of Efavirenz in Soluplus. Drug Dev. Ind. Pharm. 2017, 43, 42-54. DOI: 10.1080/03639045.2016.1205598.

34. Pawar, J.; Suryawanshi, D.; Moravkar, K.; Aware, R.; Shetty, V.; Maniruzzaman, M.; Amin, P. Study the influence of formulation process parameters on solubility and dissolution enhancement of efavirenz solid solutions prepared by hot-melt extrusion: a QbD methodology. Drug Deliv. Transl. Res. 2018, 8, 1644-1657. DOI: 10.1007/s13346-018-0481-0.

35. Rao, M. R. P.; Karanjkar, P. B. Formulation and development of gastroretentive drug delivery system of efavirenz. Int. J. Pharm. Sci. Drug Res. 2019, 11, 231-240. DOI: 10.25004/ IJPSDR.2019.110513.

36. Raut, N.A.; Dhore, P.W.; Saoji, S.D.; Dave, V.S. Assessing the enhancement of aqueous solubility of efavirenz via lyophilized milk based solid dispersion formulations, AAPS Annual Meeting and Exposition in Denver, Colorado, 2016, November 2016

Dissolution 
Poster No. 21M0400.

37. Pinto, E. C.; Cabral, L. M.; de Sousa, V. P. Development of a discriminative intrinsic dissolution method for efavirenz. Dissolut. Technol. 2014, 21, 31-40. DOI: 10.14227/DT210214P31.

38. Zaini, E.; Wahyu, D.; Octavia, M. D.; Fitriani, L. Influence of milling process on efavirenz solubility. J. Pharm. Bioallied Sci. 2017, 9, 22-25. DOI: 10.4103/0975-7406.206218.

39. Dash, S.; Murthy, P. N.; Nath, L.; Chowdhury, P. Kinetic modeling on drug release from controlled drug delivery systems. Acta Pol. Pharm. 2010, 67, 217-223.

40. Wardhana, Y. W.; Soewandhi, S. N.; Suendo, V. Observation of polymorphic transition of efavirenz during heating by Raman spectroscopy. Int. J. Sci. Res. 2018, 7, 724-727.

41. Farmakope Indonesia, 3rd ed.; Departemen Kesehatan Republik Indonesia: Jakarta, 1979.

42. The United States Pharmacopeia and National Formulary USP 36-NF 31; The United States Pharmacopeial Convention, Inc: Rockville, MD, 2013.

43. Wardhana, Y. W.; Hardian, A.; Chaerunisa, A. Y.; Suendo, V.; Soewandhi, S. N. Kinetic estimation of solid state transition during isothermal and grinding processes among efavirenz polymorphs. Heliyon 2020, 6, e03876. DOI: 10.1016/j.heliyon.2020.e03876.

44. Guo, Z.; Ma, M.; Wang, T.; Chang, D.; Jiang, T.; Wang, S. A kinetic study of the polymorphic transformation of nimodipine and indomethacin during high shear granulation. AAPS PharmSciTech 2011, 12, 610-619. DOI: 10.1208/s12249-011-9628-8.

45. Lin, S. Y.; Cheng, W. T.; Wang, S. L. Thermodynamic and kinetic characterization of polymorphic transformation of famotidine during grinding. Int. J. Pharm. 2006, 318, 86-91. DOI: 10.1016/j. ijpharm.2006.03.021.

46. Lin, S. Y. Grinding and compression processes affecting the solidstate transition of famotidine polymorphs. Asian J. Pharm. Sci. 2007, 2, 211-219.

47. Linol, J.; Coquerel, G. Influence of high energy milling on the kinetics of the polymorphic transition from the monoclinic form to the orthorhombic form of (+)5-methyl-5-(4'-methyl-phenyl) hydantoin. J. Therm. Anal. Calorim. 2007, 90, 367-370. DOI: 10.1007/s10973-007-8395-y.

48. Mangin, D.; Puel, F.; Veesler, S. Polymorphism in processes of crystallization in solution: a practical review. Org. Process Res. Dev. 2009, 13, 1241-1253. DOI: 10.1021/op900168f.

49. Marques, M. M.; Rezende, C. A.; Lima, G. C.; Marques, A. C. S.; Prado, L. D.; Leal, K. Z.; Rocha, H. V. A.; Ferreira, G. B.; Resende, J. A. L. C. New solid forms of efavirenz: synthesis, vibrational spectroscopy and quantum chemical calculations. J. Mol. Struct. 2017, 1137, 476-484. DOI: 10.1016/j.molstruc.2017.02.061.

50. Berkhout, J. H.; Ram HN, A. AswathaRam, H.N. Recent advancements in spectropho-tometric pKa determinations: a review. Indian J. Pharm. Edu. Res. 2019, 53, S475-S480. DOI: 10.5530/ijper.53.4s.141.

51. Bergström, C. A. S.; Luthman, K.; Artursson, P. Accuracy of calculated pH-dependent aqueous drug solubility. Eur. J. Pharm. Sci. 2004, 22, 387-398. DOI: 10.1016/j.ejps.2004.04.006.

52. Reijenga, J.; van Hoof, A.; van Loon, A.; Teunissen, B. Development of methods for the determination of pKa values. Anal. Chem. Insights 2013, 8, 53-71. DOI: 10.4137/ACI.S12304.

53. Rabel, S. R.; Maurin, M. B.; Rowe, S. M.; Hussain, M. Determination of the pKa and pH-solubility behavior of an ionizable cyclic carbamate, (S)-6-chloro-4-(cyclopropylethynyl)1,4-dihydro-4-(trifluoromethyl)-2H-3,1-benzoxazin-2-one (DMP 266). Pharm. Dev. Technol. 1996, 1, 91-95. DOI: 10.3109/10837459609031422.

54. Anumolu, P. D.; Venkatraju, Y.; Gurrala, S.; Puvvadi, S. B.; Subrahmanyam, C. V. S. Development of biorelevant and discriminating method for dissolution of efavirenz and its formulations. Asian J. Pharm. Clin. Res. 2012, 5, 220-223.

55. Pinto, E. C.; Carmo, F. A.; Honório, T. S.; Barros, R. C.; Castro, H. C.; Rodrigues, C. R.; Esteves, V. S.; Rocha, H. V.; Sousa, V. P.; Cabral, L. M. Influence of the efavirenz micronization on tableting and dissolution. Pharmaceutics 2012, 4, 430-441. DOI: 10.3390/ pharmaceutics4030430. 